\title{
Tumarkin-like phenomenon as a sign of therapeutic success in benign paroxysmal positional vertigo
}

\author{
Fenômeno Tumarkin-like como sinal de sucesso terapêutico na vertigem posicional \\ paroxística benigna
}

Eliana T. Maranhão', Susan L. Whitney², Péricles Maranhão-Filho³

\begin{abstract}
Objective: To describe an unusual patient reaction to maneuvers used in the treatment of posterior canal benign paroxysmal positional vertigo (PC-BPPV) that we termed the "Tumarkin-like phenomenon". Methods: At a private practice, 221 outpatients were diagnosed and treated for PC-BPPV. The treatment consisted of performing the Epley or Semont maneuvers. At the end of these maneuvers, when assuming the sitting position, the patients' reactions were recorded. Results: Thirty-three patients showed a Tumarkin-like phenomenon described by a self-reported sensation of suddenly being thrown to the ground. In the follow-up, this group of patients remained without PC-BPPV symptoms up to at least 72 hours after the maneuvers. Conclusion: The occurrence of a Tumarkin-like phenomenon at the end of Epley and Semont maneuvers for PC-BPPV may be linked with treatment success.
\end{abstract}

Keywords: benign paroxysmal positional vertigo, posterior semicircular canal; canalithiasis, vestibulolithiasis, treatment.

\section{RESUMO}

Objetivo: Descrever uma reação incomum dos pacientes às manobras utilizadas no tratamento da vertigem posicional paroxística benigna do canal posterior (VPPB-CP), a qual denominamos de fenômeno Tumarkin-like. Métodos: Em uma clínica privada, 221 pacientes ambulatoriais foram diagnosticados e tratados para VPPB-CP. O tratamento consistiu em realizar as manobras de Epley ou de Semont. Ao término da manobra, ao serem colocados na posição sentado, as reações dos pacientes foram filmadas. Resultados: Trinta e três pacientes apresentaram o fenômeno de Tumarkin-like, descrito como uma sensação súbita de ser jogado no chão. 0 acompanhamento mostrou que todos eles permaneceram sem sintomas de VPPB até pelo menos 72 horas após as manobras. Conclusão: A ocorrência do fenômeno Tumarkin-like no final das manobras de Epley e Semont para VPPB-CP pode estar associado ao sucesso terapêutico.

Palavras-chave: vertigem posicional paroxística benigna, canal semicircular posterior; canalitíase; litíase vestibular, tratamento.

Benign paroxysmal positional vertigo (BPPV) is the most frequent vestibular disorder and the leading cause of vertigo in adults ${ }^{1,2}$. The lifetime prevalence is $3.2 \%$ in females, $1.6 \%$ in males and $2.4 \%-7.8 \%$ overall. The oneyear prevalence is $5.2 \%$, and the incidence is $0.6 \%-1.5 \%$ per year ${ }^{3,4}$. The cumulative incidence of BPPV in the general population during a person's lifetime amounts to $10 \%^{1}$. Benign paroxysmal positional vertigo most often occurs spontaneously in the 50 to 70 -year age group ${ }^{2}$, and the most affected (85\%) ear and canal is the right posterior semicircular canal. Recurrence occurs in approximately $50 \%$ of persons with BPPV 5 .
In daily practice, both the Epley or repositioning maneuver $^{6}$ and the Semont or liberatory maneuver ${ }^{7}$ are used to treat presumptive posterior semicircular canalithiasis. The success rate with the Epley maneuver is approximately $80 \%$ after one session and increases to $92 \%$ with repetition up to four times. The Semont maneuver's effectiveness has been reported to be between $52 \%^{3}$ and $90 \%$ with a single maneuver 9 . In a recent randomized trial, Lee et al. ${ }^{10}$ reported that the Epley was more effective than the Semont maneuver for posterior canal BPPV (PC-BPPV); however, a recent Cochrane review ${ }^{11}$ reported no difference in the outcome between the Epley and the Semont maneuvers.

\footnotetext{
${ }^{1}$ Instituto Nacional do Câncer, Hospital do Câncer I, Departamento de Fisioterapia, Rio de Janeiro RJ, Brasil;

2 University of Pittsburgh, Department of Physical Therapy and Otolaryngology, Pittsburgh PA, United States;

${ }^{3}$ Universidade Federal do Rio de Janeiro, Departamento de Neurologia, Rio de Janeiro RJ, Brasil.

Correspondence: Eliana T. Maranhão; Av. Prefeito Dulcídio Cardoso, 1680 / 1802; 22620-311 Rio de Janeiro RJ, Brasil; E-mail: Limaranhao@gmail.com Conflict of interest: There is no conflict of interest to declare.
}

Received 29 March 2018; Received in final form 19 April 2018; Accepted 09 May 2018. 
Both maneuvers attempt to treat BPPV by rotating the patient in a manner that causes the otoconia to move within the semicircular canal back into the utricle. Patients typically report dizziness or spinning (vertigo) and some report nausea during or after the repositioning maneuvers. We report an unusual symptom constellation-a dramatic sudden illusion of movement of the environment, and the perception of falling - that occurs exclusively upon resuming a sitting position at the end of the treatment of PC-BPPV. This reaction, which resembles a crisis that Ian Tumarkin first postulated could be of utricular, saccular or combined origin, and called "The Otolithic Catastrophe"12, may result from mechanical deformation of the otolithic organs causing a burst of neural impulses that activate the vestibulospinal reflex ${ }^{12,13,14}$.

In our patients, the association of the conclusion of the liberatory with the repositioning maneuver suggests a role of the redistribution of particulate debris in the utricle, which is a phenomenon eventually associated with Menière's disease ${ }^{15,16}$.

These unusual patient reactions were not accompanied by symptoms of Menière's disease or loss of consciousness. The perception of falling or being pushed lasted seconds and resolved spontaneously. The purpose of this paper is to describe this phenomenon and its possible link with a successful treatment.

\section{METHODS}

This retrospective study consisted of 221 persons seen between January 2014 and January 2017 at an out-patient clinical setting by a physician and physiotherapist during the course of normal medical consultations and treatment of BPPV. All patients had confirmed PC-BPPV canalithiasis according to the Classification of Vestibular Disorders of the Bárány Society ${ }^{1}$ and were treated with the Epley ${ }^{6}$ and modified Semont (Semont +$)^{14}$ maneuvers.

To collect information for this paper, the authors retrospectively reviewed patient files. Using this methodology, the authors identified 33 individuals who displayed the Tumarkinlike phenomenon ("otolithic crisis") during their treatment, which is the focus of this manuscript. The remaining 188 individuals were discarded from the study. Of the 33 selected persons, 25 were women (76\%) and eight were men (24\%), aged from 46 to 90 years (mean $70.5 \pm 10.5$ [SD] years, median 69 years) (Table). All signed a consent form stating that their images and information could be used for publication.

There were no specific criteria in the choice of maneuvers used in the treatment for any given patient. The Epley procedure alone was performed on 21 patients (64\%) as initially described by Epley $^{6}$. A modification of the Semont maneuver (Semont+) alone was performed according to Alain Semont's recommendations ${ }^{14}$, on $11(33 \%)$ patients, of whom one patient had the Semont+ performed twice: once to each posterior canal during the same session. For one other patient (3\%), both the Epley and Semont+ maneuvers were applied bilaterally during the same session.
Table. Patients characteristics, diagnosis and intervention $(n=33)$.

\begin{tabular}{|c|c|c|c|c|}
\hline $\mathrm{N}$ & Gender & $\begin{array}{c}\text { Age } \\
\text { (years) }\end{array}$ & $\begin{array}{c}\text { Affected } \\
\text { posterior canal }\end{array}$ & $\begin{array}{l}\text { Applied } \\
\text { maneuver }\end{array}$ \\
\hline 1 & $M$ & 89 & $\mathrm{R}$ & Epley \\
\hline 2 & M & 60 & $\mathrm{R}$ & Semont \\
\hline 3 & $\mathrm{~F}$ & 81 & $L$ & Semont \\
\hline 4 & $\mathrm{~F}$ & 73 & L & Epley \\
\hline 5 & $\mathrm{~F}$ & 67 & $\mathrm{R}$ & Semont \\
\hline 6 & $\mathrm{~F}$ & 69 & L & Semont \\
\hline 7 & $\mathrm{~F}$ & 79 & $\mathrm{R}$ & Epley \\
\hline 8 & $\mathrm{~F}$ & 64 & L & Semont \\
\hline 9 & $\mathrm{~F}$ & 46 & $R / L$ & Semont / Epley \\
\hline 10 & $\mathrm{~F}$ & 52 & L & Semont \\
\hline 11 & M & 74 & L & Semont \\
\hline 12 & $\mathrm{~F}$ & 70 & $\mathrm{R}$ & Epley \\
\hline 13 & $\mathrm{~F}$ & 75 & $\mathrm{R}$ & Epley \\
\hline 14 & $\mathrm{~F}$ & 67 & L & Epley \\
\hline 15 & M & 75 & L & Epley \\
\hline 16 & M & 76 & $\mathrm{R}$ & Epley \\
\hline 17 & $\mathrm{~F}$ & 79 & $\mathrm{R}$ & Epley \\
\hline 18 & $\mathrm{~F}$ & 56 & $\mathrm{R}$ & Epley \\
\hline 19 & M & 78 & $\mathrm{R}$ & Epley \\
\hline 20 & $\mathrm{~F}$ & 80 & $\mathrm{~L}$ & Epley \\
\hline 21 & $\mathrm{~F}$ & 67 & L & Semont \\
\hline 22 & $\mathrm{~F}$ & 90 & L & Epley \\
\hline 23 & M & 64 & L & Epley \\
\hline 24 & $\mathrm{~F}$ & 66 & L & Epley \\
\hline 25 & $\mathrm{~F}$ & 60 & $\mathrm{R}$ & Epley \\
\hline 26 & $\mathrm{~F}$ & 63 & $\mathrm{R}$ & Semont \\
\hline 27 & $\mathrm{~F}$ & 66 & $\mathrm{R}$ & Semont \\
\hline 28 & $\mathrm{~F}$ & 68 & $L$ & Epley \\
\hline 29 & $\mathrm{~F}$ & 58 & $\mathrm{R}$ & Epley \\
\hline 30 & $\mathrm{~F}$ & 85 & $R / L$ & Semont / Semont \\
\hline 31 & M & 68 & $\mathrm{R}$ & Epley \\
\hline 32 & $\mathrm{~F}$ & 88 & $\mathrm{R}$ & Epley \\
\hline 33 & $\mathrm{~F}$ & 75 & $\mathrm{R}$ & Epley \\
\hline
\end{tabular}
canal-left; R / L: Bilateral.

Throughout the maneuver's sequence, we observed the nystagmus elicited by each positional change with video Frenzel goggles (Micromedical Infrared RealEyes xDVR Goggles $2.2 \mathrm{C}$ ), except for the final position, for the maneuver's feasibility.

The BPPV etiology was unknown in 29 patients (88\%). In three patients (9\%), the cause was trauma, and in one (3\%) the BPPV was subsequent to vestibular neuritis.

\section{RESULTS}

Immediately upon assumption of a sitting position after completion of the Epley or Semont+ maneuvers, each of the 33 patients felt a sudden-onset and strong feeling of being "thrown to the ground" by a "force", without a loss of consciousness. The unexpected sensations were very dramatic and alarming. All patients expressed a fear of falling and a sudden loss of postural control. The treating physiotherapist had to hold the patients and stabilize them in order to prevent a fall (Figure). 

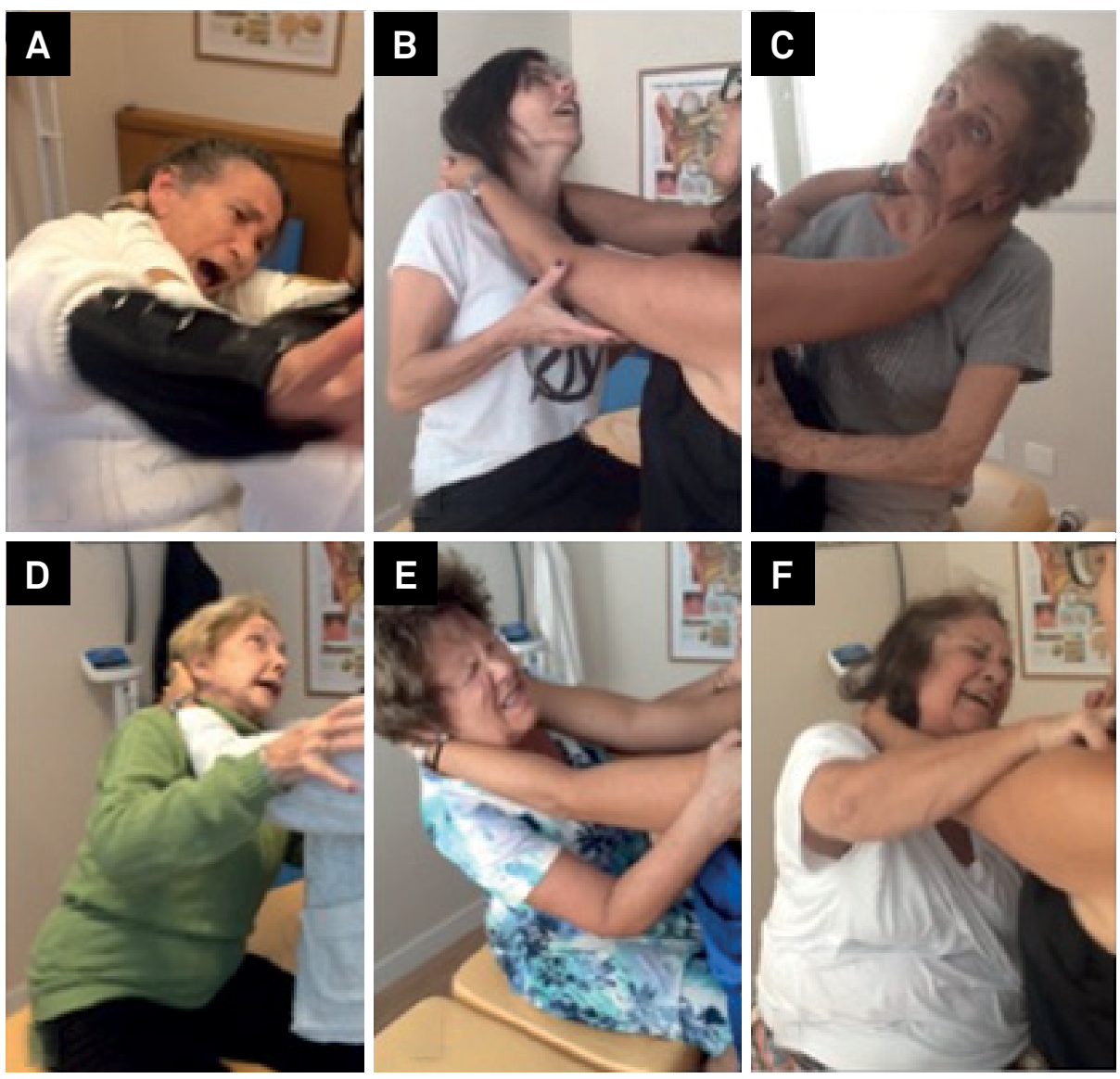

Figure. Examples of a Tumarkin-like phenomenon in six patients, immediately after the Epley (A,B,C) and the Semont+ maneuver $(\mathrm{D}, \mathrm{E}, \mathrm{F})$. Photos extracted from videos.

The appearance of the falling sensation was unrelated to the presumed laterality of the BPPV. Out of the 33 patients who experienced a sudden sensation of falling backwards at the completion of the posterior canal BPPV intervention, the right posterior canal was affected in $17(52 \%)$ of the patients, the left posterior canal was affected in $14(42 \%)$ patients and both the right and left posterior canals were affected in two (6\%) patients. Only one patient reported they were being pushed forwards and, as a result, needed to move backwards to prevent a fall. All patients showed clinical resolution of their symptoms at the conclusion of the maneuvers, as defined by either a negative Dix-Hallpike test or via a telephone call for at least up to 72 hours of treatment. The absence of symptoms is a robust measure to predict a successful treatment.

\section{DISCUSSION}

The signs and symptoms of BPPV are attributed to canalithiasis or cupulolithiasis. "Canalithiasis" describes free-floating particles within the semicircular canal ${ }^{17}$ whereas "cupulolithiasis" describes basophilic deposits on the cupula ${ }^{18}$. Electron microscopic examinations of particulate material suggest it comprises otolith fragments and proteinaceous debris, which could include membrane fragments ${ }^{19}$. Both Epley and Semont+ repositioning maneuvers are designed to relocate this biological debris from the posterior semicircular canal to the opening of the common crus in the vestibule. The continuity of the endolymph space of the utricle and the common crus can be appreciated from histological vertical sections of the human temporal bone, that show very close proximity between the orifice of the common crus and the utricular macula ${ }^{20}$.

Since the mean volumes of the saccule and utricle are only $2.42 \mathrm{~mm}^{3}$ and $10.65 \mathrm{~mm}^{3}$, respectively ${ }^{21,22}$, it seems plausible that both macula structures are transiently affected by the inertially-driven dispersion of repositioned debris. This may occur by either direct contact from moving particles, or secondary generation of endolymph pressure pulses or currents as the material settles in the vestibule.

The emergence and adaptation of nystagmus and dizziness symptoms are used to monitor progress during Epley and Semont+ repositioning maneuvers. The prognostic value of these signs and symptoms has also been a subject of discussion. Some authors ${ }^{8,21,23}$ have suggested that nystagmus that continues in the same direction throughout the Epley maneuver is prognostic of a successful outcome, based on the assumption that the particles are moving in the canal towards the utricle. Conversely, a reversal of the nystagmus in the third 
position is indicative of maneuver failure ${ }^{24}$. It is also considered a good prognostic sign when the nystagmus moves in the same direction throughout the Semont maneuver?.

Similar to the nystagmus during the maneuvers, the Tumarkin-like sensation of falling or being pushed, associated with a loss of seated postural stability, appears to be a suddenonset, prognostic sign at the end of a repositioning maneuver. Oh et al. ${ }^{24}$ reported that some patients fell backwards suddenly while sitting on a bed or moving to a chair approximately 3-60 seconds after the particle-repositioning maneuver but, in some cases, this occurred up to 10 minutes later. In our patients, the signs and symptoms resembled the Tumarkin phenomenon, but without the patients falling to the ground, as they were seated and supported by the physiotherapist. The sudden, backwards movement occurred instantaneously and independent of otologic symptoms ${ }^{16}$ and there was no alteration of consciousness. The preservation of sensorium clearly distinguishes this phenomenon from syncope ${ }^{13}$. Büki et al. ${ }^{25}$ also reported that in seven of their 20 patients with typical complaints of BPPV, no positional nystagmus was noted. Yet, they complained of vertigo of short duration during and after sitting up, sometimes with abnormal retropulsion of the trunk.

Our study has some limitations, including a relatively small sample size and no control group. However, similar to the way that the direction of nystagmus indicates a successful maneuver, we hypothesize that the reactions presented by our patients are possible indicators of a resolution to the problem. In addition, they may have the same origins described by Tumarkin ${ }^{12}$. The authors recommend a more in-depth study of this phenomenon to formally test this hypothesis. The Tumarkin-like phenomenon can be seen in an online video (Tumarkin-like phenomenon. Available at: https://youtu.be/YNtbcn6_IrM).

In conclusion, 33 patients treated for PC-BPPV with the Epley or Semont+ maneuvers perceived that they were falling backwards within one minute of resuming the sitting position. This phenomenon, which resembles a Tumarkin crisis, may have been triggered by the redistribution of repositioned cellular and otoconial debris in either the vestibule or the common crus. The successful therapeutic results reinforce this hypothesis. Based on our experience, it is highly recommended to always hold on to the patient for at least one minute after repositioning to prevent the possibility of injury.

\section{ACKNOWLEDGMENTS}

The authors thank Dr. Carey Balaban from University of Pittsburgh, for his comments, important questions and suggestions, and Mr. Péricles Maranhão Neto for his invaluable collaboration in the preparation of the text, table, figure design, and video.

\section{References}

1. Brevern M, Bertholon P, Brandt T, Fife T, Imai T, Nuti D et al. Benign paroxysmal positional vertigo: diagnostic criteria.J Vestib Res. 2015;25(3,4):105-17. https://doi.org/10.3233/VES-150553

2. HornibrookJ. Benign Paroxysmal Positional Vertigo (BPPV): history, pathophysiology, office treatment and future directions. Int J Otolaryngol. 2011;2011:ID835671. https://doi.org/10.1155/2011/835671

3. Brevern M, Radtke A, Lezius F, Feldmann M, Ziese T, Lempert T et al. Epidemiology of benign paroxysmal positional vertigo: a populationbased study. J Neurol Neurosurg Psychiatry. 2007;78(7):710-5. https://doi.org/10.1136/jnnp.2006.100420

4. Neuhauser HK, von Brevern M, Radtke A, Lezius F, Feldmann M, Ziese T et al. Epidemiology of vestibular vertigo A neurotologic survey of the general population. Neurology. 2005;65(6):898-904. https://doi.org/10.1212/01.wnl.0000175987.59991.3d.

5. Nunez RA, Cass SP, Furman JM, Holt GR. Short and long-term outcomes of canalith repositioning for benign paroxysmal positional vertigo. Otolaryngol Head Neck Surg. 2000;122(5):647-52. https://doi.org/10.1016/S0194-5998(00)70190-2

6. Epley JM. The canalith repositioning procedure: for treatment of benign paroxysmal positional vertigo. Otolaryngol Head Neck Surg. 1992;107(3):399-404. https://doi.org/10.1177/019459989210700310

7. Semont A, Freyss G, Vitte E. Curing the BPPV with a liberatory maneuver. Adv Otorhinolaryngol. 1988;42:290-3. https://doi.org/10.1159/000416126

8. Kim JS, Zee DS. Benign paroxysmal positional vertigo. N Engl J Med. 2014;370(12):1138-47. https://doi.org/10.1056/NEJMcp1309481

9. Soto-Varela A, Rossi-Izquierdo M, Santos-Pérez S. Can we predict the efficacy of the semont maneuver in the treatment of benign paroxysmal positional vertigo of the posterior semicircular canal? Otol Neurotol. 2011;32(6):1008-11. https://doi.org/10.1097/MAO.0b013e3182267f02
10. Lee JD, Shim DB, Park HJ, Song Cl, Kim MB, Kim CH et al. A multicenter randomized double-blind study: comparison of the Epley, Semont, and sham maneuvers for the treatment of posterior canal benign paroxysmal positional vertigo. Audiol Neurotol. 2014;19(5):336-41. https://doi.org/10.1159/000365438

11. Hilton MP, Pinder DK. The Epley (canalith repositioning) manoeuvre for benign paroxysmal positional vertigo. Cochrane Database Syst Rev. 2014 Dec 8;(12):CD003162. https://doi.org/10.1002/14651858.CD003162.pub3

12. Tumarkin IA. The otolithic catastrophe: a new syndrome. BMJ. 1936;25(2):175-7. https://doi.org/10.1136/bmj.2.3942.175

13. Ishiyama G, Ishiyama A, Jacobson K, Baloh RW. Drop attacks in older patients secondary to an otologic cause. Neurology. 2001;57(6):1103-6. https://doi.org/10.1212/WNL.57.6.1103

14. Maranhão-Filho P, Maranhão ET. VPPB vertigem posicional paroxística benigna \& reflexos vestibulares: testes e manobras à beira do leito. Rio de Janeiro: Revinter; 2017.

15. Baloh RW, Jacobson K, Winder T. Drop attacks with Meniere's syndrome. Ann Neurol. 1990;28(3):384-7. https://doi.org/10.1002/ana.410280314

16. Hain TC. Meniere's disease. 2018 [access March 19, 2018]. Available from: http://www.dizziness-and-balance.com/disorders/menieres/ menieres.html

17. Hall SF, Ruby RR, McClure JA. The mechanics of benign paroxysmal ver- tigo.J Otolaryngol. 1979;8:151-8.

18. Schuknecht HF. Cupulolithiasis. Arch Otolaryngol. 1969;90:113-26.

19. Kao WT, Parnes LS, Chole RA. Otoconia and otolithic membrane fragments with the posterior semicircular canal in benign paroxysmal positional vertigo. Laryngoscope. 2017;127(3):709-14. https://doi.org/10.1002/lary.26115 
20. Schuknecht HF. Pathology of the ear. Cambridge: Harvard University Press; 1974.

21. Igarashi M, O-Uchi T, Isago H, Wright WK. O-Uchi T, Isago $\mathrm{H}$, Wright WK. Utricular and saccular volumetry in human temporal bones. Acta Otolaryngol. 1983;95(1-4):75-80. https://doi.org/10.3109/00016488309130918

22. Morita N, Kariya S, Deroee AF, Cureoglu S, Nomiya S, Nomiya R et al. Membranous labyrinth volumes in normal ears and Ménière disease: a three-dimensional reconstruction study. Laryngoscope. 2009;119(11):2216-20. https://doi.org/10.1002/lary.20723
23. Baloh RW, Honrubia V. Clinical neurophysiology of the vestibular system. 3rd ed. Oxford: Oxford University Press; 2001.

24. Oh HJ, Kim JS, Han BI, Lim JG. Predicting a successful treatment in posterior canal benign paroxysmal positional vertigo. Neurology. 2007;68(15):1219-22. https://doi.org/10.1212/01.wnl.0000259037.76469.e4

25. Büki B, Simon L, Garab S, Lundberg YW, Jünger H, Straumann D. Sittingup vertigo and trunk retropulsion in patients with benign positional vertigo but without positional nystagmus. J Neurol Neurosurg Psychiatry. 2011 Jan;82(1): 98-104. https://doi.org/10.1136/jnnp.2009.199208 